\title{
Effects of walking in water on gut hormone concentrations and appetite: comparison with walking on land
}

\author{
Shin-ya Ueda ${ }^{1}$, Hidehiro Nakahara ${ }^{1}$, Eriko Kawai ${ }^{2}$, Tatsuya Usui ${ }^{3}$, Shintaro Tsuji ${ }^{3}$ and Tadayoshi Miyamoto \\ ${ }^{1}$ Department of Acupuncture, Morinomiya University of Medical Sciences, Osaka, Japan \\ ${ }^{2}$ Department of Environmental Physiology for Exercise, Osaka City University Graduate School of Medicine, Osaka, Japan \\ ${ }^{3}$ Department of Elementary and Preschool Education, Osaka Seikei College, Osaka, Japan \\ Correspondence should be addressed to S Ueda: s-ueda@morinomiya-u.ac.jp
}

\begin{abstract}
The effects of water exercise on gut hormone concentrations and appetite currently remain unclear. The aim of the present study was to investigate the effects of treadmill walking in water on gut hormone concentrations and appetite. Thirteen men (mean \pm s.D. age: $21.6 \pm 2.2$ years, body mass index: $22.7 \pm 2.8 \mathrm{~kg} / \mathrm{m}^{2}$, peak oxygen uptake $\left(\mathrm{VO}_{2 \text { peak }}\right): 49.8 \pm 7.8 \mathrm{~mL} / \mathrm{kg}$ per $\mathrm{min}$ ) participated in the walking in water and on land challenge. During the study period, ratings of subjective feelings of hunger, fullness, satiety and motivation to eat were reported on a $100-\mathrm{mm}$ visual analog scale. A test meal was presented after walking, and energy intake (EI) was calculated. Blood samples were obtained during both trials to measure glucagon-like peptide-1 (GLP-1), peptide YY (PYY) and acylated ghrelin (AG) concentrations. Hunger scores (How hungry do you feel?) were significantly lower during the water trial than during the land trial $(P<0.05)$. No significant differences were observed in El between water and land trials. GLP-1 concentrations were significantly higher in the water trial than in the land trial $(P<0.05)$. No significant differences were observed in PYY concentrations between water and land trials. AG concentrations were significantly lower in the water trial than in the land trial $(P<0.01)$. In conclusion, changes in gut hormone concentrations during walking in water contribute to the exercise-induced suppression of appetite and provide novel information on the influence of walking in water on the acute regulation of appetite.
\end{abstract} Key Words

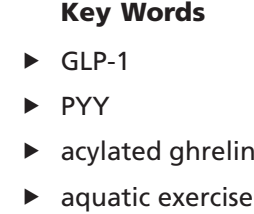

Endocrine Connections (2018) 7, 97-106

\section{Introduction}

Appetite and eating behavior are controlled by various peripheral signals that change in response to food intake and act on the hypothalamus and brainstem (1). These feedback signals involve a number of gut hormones, such as glucagon-like peptide-1 (GLP-1), peptide YY (PYY) and ghrelin (2). The effects of exercise on these hormones have been investigated extensively over the past decade $(3,4)$. Previous findings suggested that the concentrations of anorexigenic hormones (GLP-1 and PYY) increased, while those of plasma acylated ghrelin (AG) decreased following endurance exercise $(5,6,7)$. We also demonstrated that a single bout of aerobic exercise caused significant increases in GLP-1 and PYY plasma concentrations (8, 9, 10). These findings suggest that exercise partly functions as a physiological regulator for hormone release or metabolism and, thus, controls appetite.

Walking in water is endorsed for maintaining and improving physical fitness and health because of the

$$
\begin{array}{lr}
\text { http://www.endocrineconnections.org } & \text { @ } 2018 \text { The authors } \\
\text { https://doi.org/10.1530/EC-17-0323 } & \text { Published by Bioscientifica Ltd }
\end{array}
$$

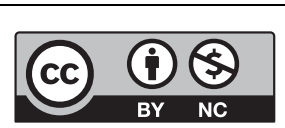

This work is licensed under a Creative Commons Attribution-NonCommercial 4.0 International License. 
properties of water, such as water pressure, buoyancy and resistance (11). Therefore, walking in water has been extensively utilized in rehabilitation for various sports injuries, including disease prevention in terms of health care. Although other modes of activities such as resistance exercise $(5,12,13)$, sprint interval training (14) and rope skipping exercise (15) have been evaluated, the effects of treadmill walking in water on gut hormone concentrations and appetite remain unclear. Lambert and coworkers (16) reported no significant differences in energy intake (EI) or appetite after exercise between swimming and running trials. In addition, King and coworkers (17) showed that an acute bout of swimming suppressed AG concentrations and appetite. However, the mode of exercise employed by these studies was swimming and anorexigenic hormones (GLP-1 and PYY) were not examined. Furthermore, there were discrepancies between the findings of these studies. A clearer understanding of the effects of treadmill walking in water on gut hormone concentrations and appetite may contribute to exercise guidance for maintaining and improving body weight and mass for health.

Therefore, the aim of the present study was to investigate the effects of treadmill walking in water on gut hormone concentrations and appetite and compare them to those when walking on land.

\section{Materials and methods}

\section{Participants}

Twenty-one young male subjects were recruited. All subjects were lifelong non-smokers with a reported stable weight and the lack of any special type of diet for the previous 6 months. None had any history of infectious disease for at least a 1-month period preceding this study, and none were taking medication. Subjects with a history of gastrointestinal, endocrine, cardiovascular or psychological diseases or type 1 or 2 diabetes were excluded. All subjects provided written informed consent for participation in the study, which was approved by the Ethics Committee of Morinomiya University of Medical Sciences (Admitting No. 2014-053).

\section{Design}

Participants were randomly assigned to participate in one of the two studies. In study 1 , thirteen men (mean \pm s.D. age: $21.6 \pm 2.2$ years, body mass index: $22.7 \pm 2.8 \mathrm{~kg} / \mathrm{m}^{2}$, peak oxygen uptake $\left(\mathrm{VO}_{2 \text { peak }}\right): 49.8 \pm 7.8 \mathrm{~mL} / \mathrm{kg}$ per min)

$$
\text { http://www.endocrineconnections.org }
$$

participated in the walking in water and on land challenge. In study 2 , eight men (mean \pm s.D. age: $19.5 \pm 1.8$ years, body mass index: $22.4 \pm 1.3 \mathrm{~kg} / \mathrm{m}^{2}, \quad \mathrm{VO}_{2 \text { peak }}: 53.2 \pm 7.1 \mathrm{~mL} / \mathrm{kg}$ per min) participated in the water immersion (WI) challenge. Studies 1 and 2 recruited different subjects. Subjects were habitually active, but were not trained athletes, with most individuals typically participating in games and activities such as soccer, baseball and basketball on a regular basis at a recreational level. In order to control physical activity on the days prior to and on the mornings of the trials, subjects were instructed to refrain from moderate to heavy exercise for at least $24 \mathrm{~h}$ prior to each investigation. In addition, all subjects were instructed to consume a weight-maintaining diet containing 55-65\% carbohydrates, $10-20 \%$ protein and $20-30 \%$ fat (energy percent) and recorded all food and drink consumed 1 week prior to and throughout the study period. Dietary records were analyzed using a computerized nutritional analysis system (Excel Eiyoukun, Kenpakusha, Tokyo, Japan). All dietary assessments were performed by experimental measurers and supervised by researchers. Prior to the main trial days, each subject attended the laboratory for a preliminary examination in which anthropometric measurements (height and body weight) were recorded. We also measured $\mathrm{VO}_{\text {2peak }}$ during the incremental treadmill protocol as an index of cardiorespiratory fitness and to select the pace in the walking in water and on land trials. This test consisted of 3-min stages with the speed of the treadmill being progressively increased at each stage by $1-2 \mathrm{~km} / \mathrm{h}$ until voluntary exhaustion. Respiratory data during the experiments were recorded using an automatic breath-by-breath respiratory gas analyzing system (ARCO2000, Arcosystem, Chiba, Japan) consisting of a flow meter for the hot wire in the face mask, an $\mathrm{O}_{2}$ analyzer made from a zirconium element and an infrared $\mathrm{CO}_{2}$ analyzer.

\section{Study 1: Effects of walking in water}

All subjects took part in two experimental trials (walking in water and on land trials) at least 7 days apart. The order of the two trials was randomized across subjects. The design of the experimental session is shown diagrammatically in Fig. 1. Room temperature was set at $25^{\circ} \mathrm{C}$ in two experimental trials. Subjects came to the laboratory at 08:30 h and, after a 10-min rest period, a cannula was inserted into the antecubital vein, and a fasting venous blood sample (baseline; $t=0)$ was taken $(20 \mathrm{~mL})$. Exercise commenced at 09:00 h, with subjects completing $30 \mathrm{~min}$ of treadmill walking at a speed equivalent to $50 \%$ of their $\mathrm{VO}_{2 \text { peak }}$. During this exercise, subjects wore a heart rate

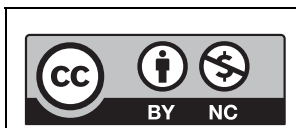

This work is licensed under a Creative Commons Attribution-NonCommercial 4.0 International License. 


\section{Walking in water or on land}

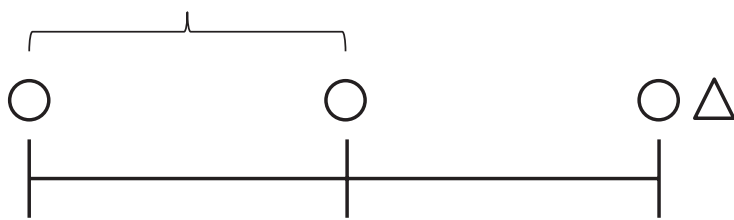

0

(Baseline)

30

60

(min.)

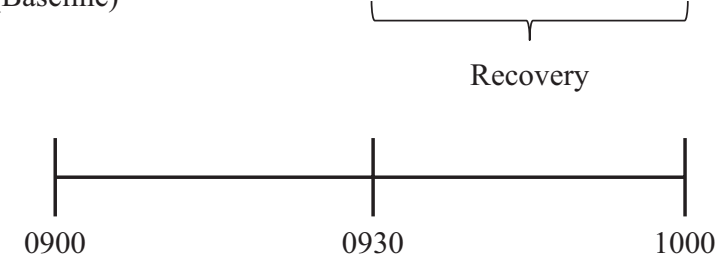

\section{: Blood sampling $\quad \triangle$ : Test meal}

Figure 1

Scheme of study 1.

(HR) monitor and breathed through a face mask into the automatic breath-by-breath respiratory gas analyzing system (ARCO-2000, Arcosystem) described previously. Experimental measurers made careful adjustments to coincide the speed to $50 \%$ of their $\mathrm{VO}_{2 \text { peak }}$ from the data of the automatic breath-by-breath respiratory gas analyzing system. Subjects were immersed to chest depth (xiphoid process) on an underwater treadmill (AquaCiser Underwater Treadmill System, Ferno-Washington. Inc., Ohio, USA in thermoneutral water $\left(34^{\circ} \mathrm{C}\right)$ during walking in water. Craig and Dvorak (18) recorded rectal temperature during WI and recommended $34^{\circ} \mathrm{C}$ as the thermoneutral temperature at rest. At this temperature setting, neither coldness nor shivering was reported by any of the participants. Blood samples were obtained after the end of the exercise (exercise condition; $t=30$ ) and 30 min after the exercise had finished $(t=60)$. In addition, during the study period $(t=0,30$ and $60 \mathrm{~min})$, ratings of subjective feelings of hunger, fullness, satiety and motivation to eat were reported on a $100-\mathrm{mm}$ visual analog scale (19) and the feeling of dyspnea and leg fatigue were assessed according to Borg scales (20).

At $10: 00 \mathrm{~h}(t=60 \mathrm{~min})$, a test meal (instant pasta: $7.9 \%$ protein, $44.6 \%$ fat and $47.5 \%$ carbohydrates (energy percent)) was provided and subjects were instructed to eat as much as they liked until satisfied, as described previously $(8,9,10)$. In order to exclude the possibility that the amount of food eaten depended on its palatability, we asked all subjects of the foods they liked prior to the study and selected instant pasta as the test meal. We filled a small bowl with the test pasta and repeatedly filled the bowl

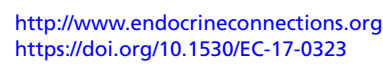

C) 2018 The authors Published by Bioscientifica Ltd with pasta before the participant had emptied it to ensure blindness to the amount of food eaten. No time limit was set for eating under either experimental condition. During the trials, subjects and experimenters were instructed to abstain from talking about the meal. Participants were not overly informed that the true purpose of the present study was to assess feeding responses where possible until they had completed the protocol. Water was freely available during trials. After consumption of the test meal, any remaining food was weighed and the amount eaten was subtracted from the premeal value to obtain the total amount of food ingested. Absolute EIs from the test meal in both trials were then calculated from the amount of food eaten $(1.15 \mathrm{kcal} / \mathrm{g})$.

\section{Study 2: Effects of WI (supplemental protocol)}

We investigated the effects of WI on gut hormone concentrations and appetite. Subjects came to the laboratory at $08: 30 \mathrm{~h}$ and, after a 10 -min rest period, a cannula was inserted into the antecubital vein, and a fasting venous blood sample (without WI; $t=0$ ) was taken $(20 \mathrm{~mL})$. The subject rested in the water tank in a standing position with WI $\left(34^{\circ} \mathrm{C}\right)$ for $30 \mathrm{~min}$. The subject's body was immersed in water up to the level of the chest (xiphoid process). Changes in thoracic volume were estimated using impedance plethysmography (21). Subjects wore an HR monitor and breathed through a face mask into the automatic breath-by-breath respiratory gas analyzing system (ARCO-2000, Arcosystem). Blood samples were obtained after the end of WI (WI condition; $t=30$ ). In addition, during the study period ( $t=0$ and $30 \mathrm{~min}$ ), ratings of subjective feelings of hunger, fullness, satiety and motivation to eat were reported on a $100-\mathrm{mm}$ visual analog scale (19).

\section{Blood sampling}

Blood samples were immediately transferred into disodium EDTA-treated tubes to measure plasma gut hormones, glucose, insulin and IL-6. Aprotinin, a potent protease inhibitor, was added to samples at a concentration of $500 \mathrm{kIU} / \mathrm{mL}$ for the measurement of AG. Test tubes were then centrifuged at $1308 \mathrm{~g}$ at $4^{\circ} \mathrm{C}$ for $15 \mathrm{~min}$ immediately after collection, and plasma samples were stored at $-80^{\circ} \mathrm{C}$ for later analyses. Hematocrit was measured using Celltac alpha (Nihon Kohden Inc., Tokyo, Japan). Glucose was measured using the enzymatic reference method with hexokinase. Insulin was assessed by the fully automated chemiluminescence method (CLIA). Plasma IL-6 (Human

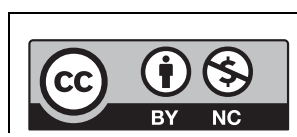

This work is licensed under a Creative Commons Attribution-NonCommercial 4.0 International License. 
IL-6 Immunoassay kit, R\&D Systems), GLP-1 (GLP-1 (7-36) amide) (Human GLP-1 EIA kit, Yanaihara Institute Inc., Shizuoka, Japan), PYY (Human PYY EIA kit, Yanaihara Institute Inc.) and AG (Active Ghrelin ELISA kit, Mitsubishi Kagaku Iatron Inc., Tokyo, Japan) concentrations were assessed by ELISA. ELISA for PYY quantified the total amount of PYY1-36 and PYY3-36. The coefficients of variation values of IL-6, GLP-1, PYY and AG were 4.2, 8.6, 5.2 and $8.4 \%$, respectively. All sample measurements were performed in duplicate according to the manufacturers' instructions.

\section{Statistical analyses}

All statistical analyses were performed using SPSS for Windows (SPSS). All data were normally distributed and presented as means \pm s.D. Areas under the curve (AUC) were calculated using the trapezoidal rule to assess total changes in each gut hormone during each trial ( $t=0-60)$. We also calculated average R-R intervals (mean RR), the standard deviation of R-R (s.D. RR) and coefficient of variation of $\mathrm{R}-\mathrm{R}$ intervals (CVRR: (S.D. RR/mean RR) × 100), which are often used to indicate parasympathetic nervous activity. The effects of the trial on EI, biochemical parameters, expired gas data, HR, CVRR, dyspnea feeling and leg fatigue scores and central blood volume were assessed using Student's paired $t$-test. In order to examine the effects of trials and condition on the concentrations of plasma gut hormones and VAS scores, a two-way analysis of variance with repeated measures was performed. If significance was detected, post hoc multiple pair-wise comparisons (Tukey-Kramer test) were performed. In addition, the relationships among each gut hormone and hunger scores were assessed by a simple correlation using Pearson's correlation coefficient. P-Values less than 0.05 were considered to be significant.

\section{Results}

\section{Study 1: Effects of walking in water}

\section{Exercise characteristics}

No significant changes were observed in hematocrit over time during exercise. Therefore, hemoconcentration was unlikely to have occurred during the exercise performed in the present study (data not shown). No significant differences were noted in the mean values of $\mathrm{VO}_{2}$, $\% \mathrm{VO}_{2 \text { peak }}$ and respiratory exchange ratio (RER) during walking between water and land trials (Table 1). Mean

$$
\text { http://www.endocrineconnections.org }
$$

Table 1 Exercise characteristics and biochemical parameters with walking in water and on land.

\begin{tabular}{|c|c|c|c|}
\hline & Land & Water & Significance \\
\hline $\mathrm{VO}_{2}(\mathrm{~L} / \mathrm{min})$ & $1.67 \pm 0.11$ & $1.64 \pm 0.12$ & NS \\
\hline$\% \mathrm{VO}_{2 \text { peak }}(\%)$ & $51.6 \pm 4.8$ & $50.7 \pm 5.2$ & NS \\
\hline RER & $0.97 \pm 0.05$ & $0.99 \pm 0.09$ & NS \\
\hline HR (beats/min) & $118.3 \pm 6.7$ & $111.4 \pm 4.1$ & * \\
\hline CVRR (\%) & $2.5 \pm 2.4$ & $3.9 \pm 2.0$ & * \\
\hline $\begin{array}{l}\text { Dyspnea feeling } \\
\text { (score) }\end{array}$ & $3.6 \pm 1.3$ & $3.4 \pm 1.6$ & NS \\
\hline Leg fatigue (score) & $3.4 \pm 1.3$ & $6.7 \pm 1.6$ & * \\
\hline $\begin{array}{l}\text { Walking speed } \\
(\mathrm{km} / \mathrm{h})\end{array}$ & $6.6 \pm 0.9$ & $6.0 \pm 0.5$ & $* *$ \\
\hline \multicolumn{4}{|c|}{ Biochemical parameters } \\
\hline Glucose (mg/dL) & $91.6 \pm 8.1$ & $90.4 \pm 8.9$ & NS \\
\hline Insulin $(\mu \mathrm{U} / \mathrm{mL})$ & $3.7 \pm 2.8$ & $3.6 \pm 2.4$ & NS \\
\hline $\mathrm{IL}-6(\mathrm{pg} / \mathrm{mL})$ & $0.45 \pm 0.4$ & $1.34 \pm 0.5$ & * \\
\hline
\end{tabular}

Values are presented as means \pm S.D.

$* P<0.05, * * P<0.01$; water vs land trials.

CVRR, coefficient of variation of R-R intervals; HR, heart rate; IL-6,

interleukin-6; $\mathrm{RER}$, respiratory exchange ratio; $\mathrm{VO}_{2}$, oxygen uptake.

HR values during walking were significantly lower in the water trial than in the land trial $(P<0.05$; Table 1$)$. Furthermore, CVRR during walking was significantly higher in the water trial than in the land trial $(P<0.05$; Table 1). No significant differences were observed in the feeling of dyspnea after walking between water and land trials (Table 1). In contrast, leg fatigue after walking was significantly higher in the water trial than in the land trial $(P<0.05$; Table 1$)$. Walking speed was significantly slower in the water trial than in the land trial $(P<0.01$; Table 1).

\section{El and measures of appetite}

No significant differences were observed in EI after walking between the two trials (Fig. 2A). Hunger scores (How hungry do you feel?) were significantly lower when walking in water than on land $(P<0.05$; Fig. $2 \mathrm{~B})$. No significant differences were observed in fullness (How full do you feel?), satisfaction (How satisfied do you feel?) or motivation to eat (How much do you feel you can eat?) scores between the two trials (data not shown).

\section{Gut hormone concentrations}

No significant differences were observed in GLP-1 or PYY concentrations after walking between water and land trials (Fig. 3A-C). However, mean AUC values for GLP-1 were significantly higher in the water trial than in the land trial $(P<0.05$; Fig. 3B).

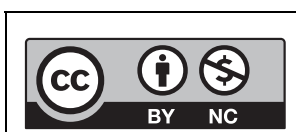

This work is licensed under a Creative Commons Attribution-NonCommercial 4.0 International License. 
(B)

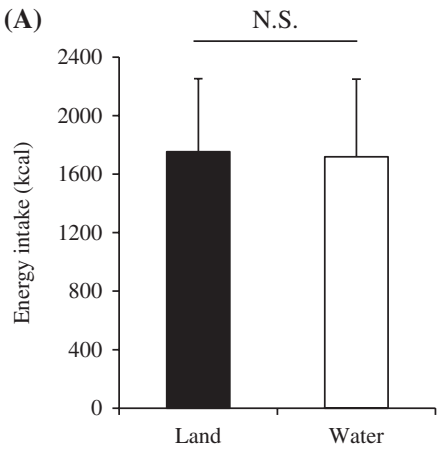

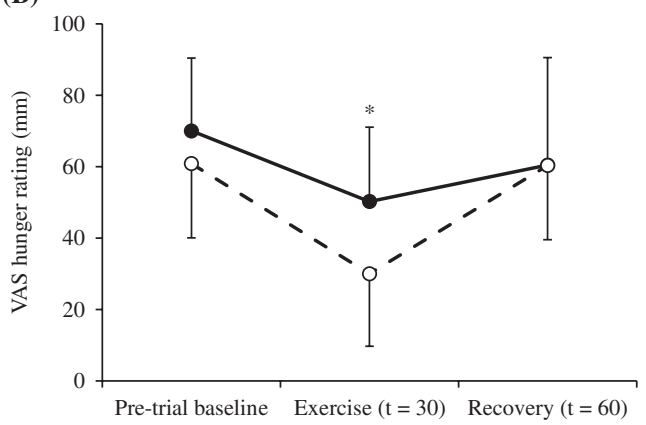

Figure 2

Absolute amount of energy ingested in the test meal (A) and differences in hunger scores (B) during walking in water $(\mathrm{O})$ and on land $(\boldsymbol{\bullet})$ trials. The mean values \pm s.D. of each parameter are presented. ${ }^{*} P<0.05$, water vs land trials.
Mean AG concentrations were significantly lower when walking in water than on land $(P<0.05$; Fig. 3E). Furthermore, mean AUC values for AG were significantly lower in the water trial than in the land trial $(P<0.01$; Fig. 3F).

\section{Glucose metabolism and IL-6}

No significant differences were observed in glucose or insulin concentrations between the two trials (Table 1). IL-6 concentrations during walking were significantly higher in the water trial than in the land trial $(P<0.05$; Table 1$)$.
(A)

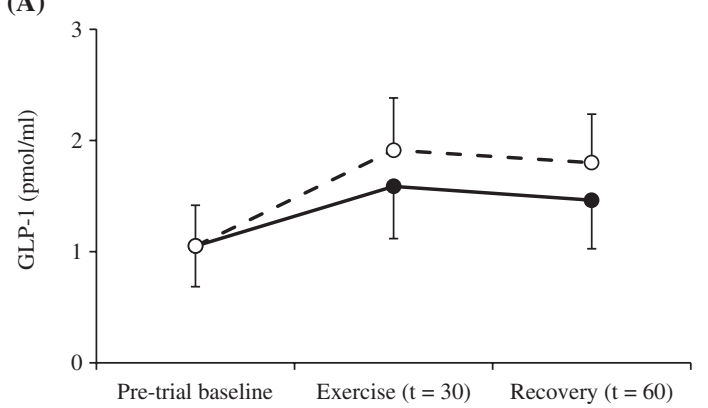

(C)

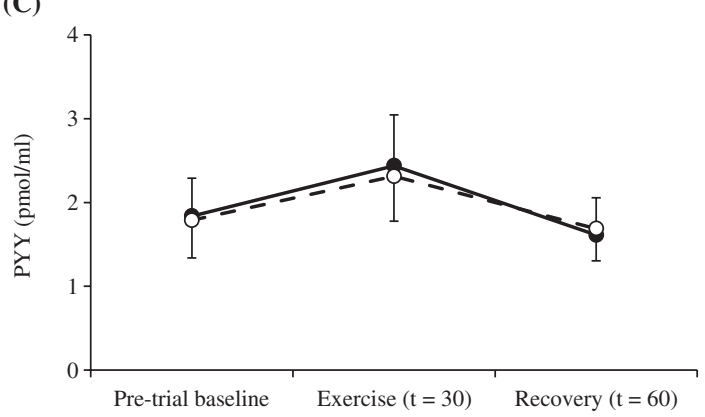

(E)

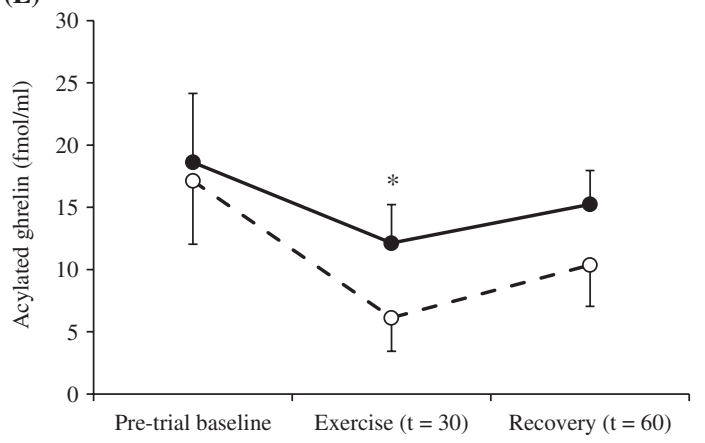

(B)
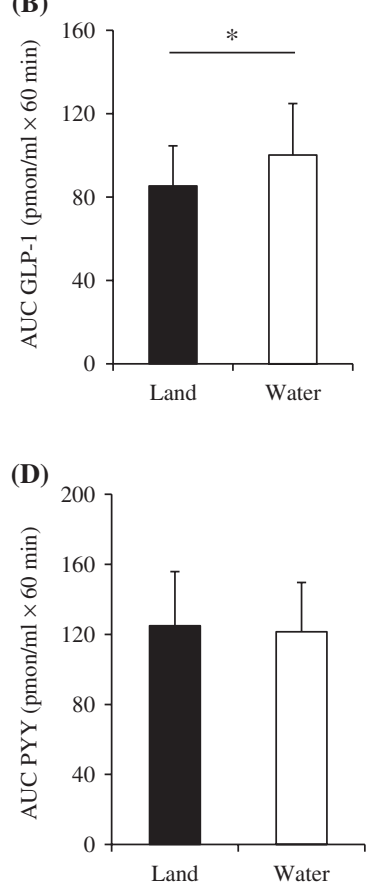

(F)

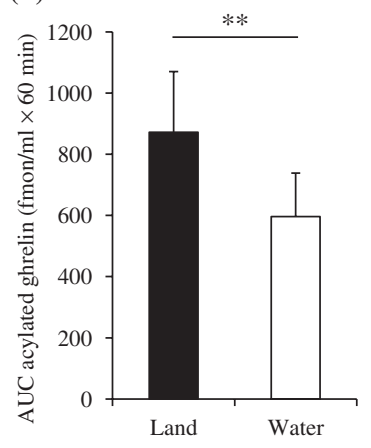

Figure 3

Differences in plasma GLP-1 (A), PYY (C) and acylated ghrelin (E) concentrations during walking in water $(O)$ and on land $(O)$ trials and area under the curve values for GLP-1 (B), PYY (D) and acylated ghrelin (F). The mean values \pm S.D. of each parameter are presented. ${ }^{*} P<0.05$, $* * P<0.01$, water vs land trials. http://www.endocrineconnections.org https://doi.org/10.1530/EC-17-0323 (c) 2018 The authors Published by Bioscientifica Ltd

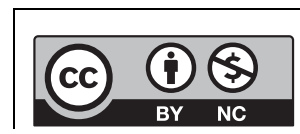
This work is licensed under a Creative Commons
Attribution-NonCommercial 4.0 International License. 
Table 2 Effects of water immersion

\section{Relationships among gut hormone levels and hunger scores}

An examination of the relationships among plasma AG concentrations and hunger rating scores at individual time points $(t=0,30$ and 60$)$ revealed a correlation at $t=30$ (after the end of walking) in the walking on land and in water $(r=0.631, P<0.01$; Fig. 4$)$ trial, but at no other points in the walking in water and on land trial. Plasma GLP-1 and PYY concentrations did not correlate with hunger rating scores at any time point in either trial (data not shown).

\section{Study 2: Effects of WI (supplemental protocol)}

No significant differences were noted in the mean values of $\mathrm{VO}_{2}, \mathrm{RER}$ or gut hormone concentrations (Table 2). There was a $12.9 \pm 1.7 \%$ increase in thoracic admittance $(P<0.001$; Table 2$)$ corresponding to an increase in central blood volume during WI, whereas HR was significantly decreased during WI by $15.8 \pm 6.9 \%(P<0.01$; Table 2$)$. No significant differences were noted in the ratings of subjective feelings of hunger, fullness, satiety and motivation to eat during WI (Table 2).

\section{Discussion}

The objective of the present study was to investigate the effects of treadmill walking in water on gut hormone concentrations and appetite and compare them to those when walking on land. The following results were obtained: (1) hunger scores were significantly lower when

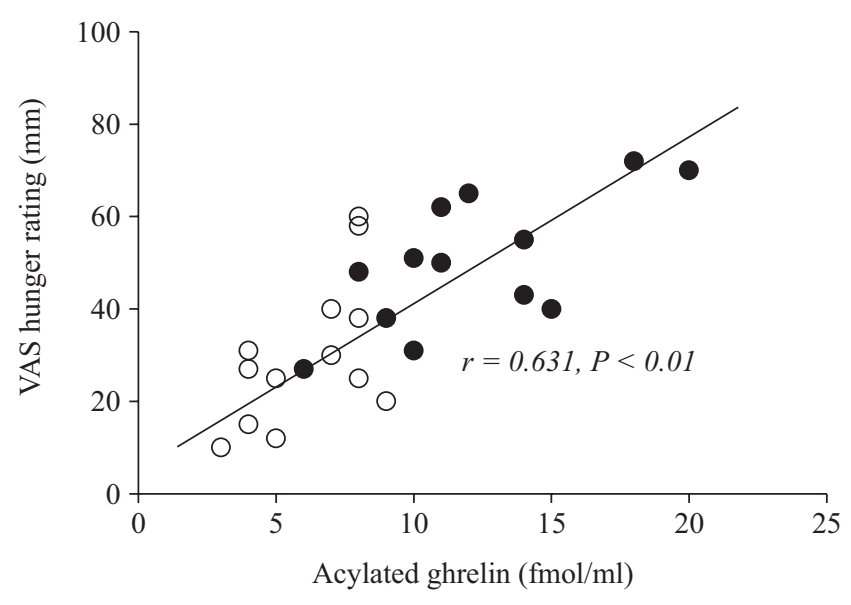

Figure 4

Relationships between acylated ghrelin concentrations and hunger scores at $t=30$ (after the end of walking) in the walking in water (O) and on land (๑) trials.

$$
\begin{array}{lr}
\text { http://www.endocrineconnections.org } & \text { (อ) } 2018 \text { The authors } \\
\text { https://doi.org/10.1530/EC-17-0323 } & \text { Published by Bioscientifica Ltd }
\end{array}
$$

\begin{tabular}{|c|c|c|c|}
\hline & Without WI & With WI & Significance \\
\hline $\mathrm{VO}_{2}(\mathrm{~mL} / \mathrm{min})$ & $332 \pm 51$ & $348 \pm 54$ & NS \\
\hline RER & $0.81 \pm 0.05$ & $0.82 \pm 0.09$ & NS \\
\hline HR (beats/min) & $69.6 \pm 6.9$ & $58.5 \pm 6.3$ & ** \\
\hline $\mathrm{CBV}\left(\mathrm{S} \times 10^{-3}\right)$ & $42.8 \pm 3.2$ & $48.3 \pm 3.8$ & $\star \star *$ \\
\hline \multicolumn{4}{|l|}{ Gut hormones } \\
\hline GLP-1 (pmol/mL) & $1.1 \pm 0.5$ & $1.2 \pm 0.4$ & NS \\
\hline PYY (pmol/mL) & $1.8 \pm 0.6$ & $1.7 \pm 0.6$ & NS \\
\hline AG (fmol/mL) & $18.6 \pm 5.5$ & $17.8 \pm 5.3$ & NS \\
\hline \multicolumn{4}{|l|}{ Appetite } \\
\hline Hunger (mm) & $70.0 \pm 20.4$ & $61.1 \pm 20.8$ & NS \\
\hline Fullness (mm) & $22.6 \pm 19.5$ & $23.8 \pm 21.8$ & NS \\
\hline Satiety (mm) & $21.7 \pm 23.7$ & $20.9 \pm 24.7$ & NS \\
\hline $\begin{array}{l}\text { Motivation to } \\
\text { eat }(\mathrm{mm})\end{array}$ & $82.4 \pm 21.7$ & $83.9 \pm 22.2$ & NS \\
\hline
\end{tabular}

Values are presented as means \pm S.D.

$* * * P<0.001, * * P<0.01$.

$A G$, acylated ghrelin; CBV, central blood volume; HR, heart rate; RER,

respiratory exchange ratio; $\mathrm{VO}_{2}$, oxygen uptake; $\mathrm{WI}$, water immersion.

walking in water than on land; (2) GLP-1 concentrations were significantly higher and AG concentrations were significantly lower when walking in water than on land; and (3) a positive correlation was observed between plasma AG concentrations and hunger scores after the end of walking in water and on land.

EI and appetite responses to walking in water have not previously been examined, and no significant differences were observed in EI after walking between water and land trials in this study. A recent systematic review reported that exercise did not increase or decrease absolute EI following an exercise task (22). Swimming did not affect energy or macronutrient intake between swimming and resting trials (17). In addition, Lambert and coworkers (16) reported no significant differences in EI after exercise between swimming and running trials, which is consistent with the present study. On the other hand, the present results suggest that walking in water caused a significantly greater reduction in hunger sensations than walking on land. One possible explanation for this inhibition is the difference in energy expenditure and intensity between water and land trials. However, energy metabolism in the water and land trials matched, with no significant difference being observed in $\mathrm{VO}_{2}$. In addition, no significant differences were noted in the feeling of dyspnea after walking between water and land trials. Another possibility is that inhibitory responses are linked to the changes observed in gut hormone concentrations during walking in water. Lambert and coworkers (16) reported no significant differences in the hunger scale, which is inconsistent with the present results. Although

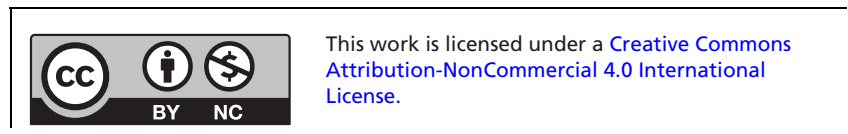


we cannot provide a definite explanation for this discrepancy, the different characteristics of the subjects enrolled for the study may have affected this outcome. In the study by Lambert and coworkers (16), well-trained competitive male triathletes were enrolled. Therefore, well-trained triathletes may have different responses to aquatic exercise than non-triathletes because of specific metabolic and endocrine (such as appetite-related hormones) adaptations to aquatic exercise. However, to the best our knowledge, this issue has not yet been investigated; thus, our hypothesis remains speculative. Future research is needed to clarify this point.

A systematic review recently reported that acute exercise increased GLP-1 concentrations (23). We also demonstrated that a single bout of aerobic exercise caused significant increases in GLP-1 plasma concentrations $(8,9,10)$. These findings suggest that exercise partly functions as a physiological regulator for GLP-1 release or metabolism and, thus, leads to appetite control. We herein demonstrated that AUC values for GLP-1 concentrations were significantly higher when walking in water than on land. Previous studies reported that increases in the plasma concentrations of GLP-1 $(24,25,26,27,28)$ were mediated by a neural pathway, regardless of exercise. The vagus nerve efferent pathway was examined for its global effects on basal GLP-1 secretion and represented the main parasympathetic nerve innervating the proximal portion of the gastrointestinal tract $(27,29,30)$. HR during exercise in water was also lower than that on land at the same $\mathrm{VO}_{2}$ and one major mechanism for this phenomenon is vagal nerve activity (31). Background vagal nerve activity in the present study was higher for walking in water than on land. CVRR during exercise was significantly higher in the water trial than in the land trial. These results indicated that the higher AUC values for GLP-1 concentrations when walking in water than on land were mediated by activation of the vagal nerve. Another possible explanation for this phenomenon is the difference in IL- 6 kinetics between water and land trials. In order to clarify whether IL- 6 was required for this exercise-induced increase in GLP-1, Ellingsgaard and coworkers (32) subjected IL-6 knockout mice to a bout of exercise and found that plasma GLP-1 concentrations did not increase in response to this manipulation. Although the present study demonstrated that GLP-1 and IL-6 concentrations had the same patterns during the 60-min water/land trials, GLP-1 concentrations did not correlate with IL-6 concentrations at any time point in either trial (data not shown). Further studies are needed in order to elucidate the interplay between the two mechanistic pathways (neural and humoral) underlying increases in GLP-1 plasma concentrations during exercise. In addition, total GLP-1 was measured rather than active GLP-1 in the present study. Since we did not add a dipeptidyl peptidase 4 (DPP-4) inhibitor, we were unable to measure active GLP-1 concentrations. A previous study demonstrated that active and total GLP-1 concentrations showed the same pattern during the glucose tolerance test (33). Therefore, these findings prompted us to speculate that total GLP-1 concentrations may reflect active GLP-1 responses to exercise. Future studies incorporating a DPP-4 inhibitor need to be conducted in order to enable the assessment of active GLP-1 concentrations because previous findings have suggested that total GLP-1 concentrations reflect changes in active GLP-1 concentrations.

Plasma PYY concentrations also generally increase with exercise, similar to GLP-1 $(4,23)$. In the present study, PYY concentrations increased during the walking in water and on land trials, which is consistent with previous findings $(4,5,7,8,9,10,23)$. However, no significant differences were observed in PYY concentrations between the two trials; therefore, the physiological mechanisms responsible for this phenomenon currently remain unknown. We previously demonstrated that while increases in PYY concentrations were dependent on exercise intensity, GLP-1 concentrations were similar between high- and moderate-intensity exercise sessions (9). Of particular interest in the present study were the different results obtained between GLP-1 and PYY despite these hormones having the same secretory cells and anorexigenic functions, similar to our previous findings (9). In other words, the physiological mechanisms underlying the secretion of GLP-1 and PYY during exercise were caused by a different mechanism. Collectively, the present results appear to provide a novel insight into the mechanisms underlying exercise-induced changes in GLP-1 and PYY concentrations in humans.

Ghrelin is secreted into the circulation in which it is present in two forms: acylated and unacylated $(34,35)$. The appetite regulation of ghrelin is now understood to be chiefly influenced by AG $(3,34)$. A recent metaanalysis found that exercise may influence appetite by suppressing AG concentrations (23). In addition, AG was previously shown to be suppressed during swimming (17). We herein demonstrated that walking in water decreased AG plasma concentrations. The positive correlation between plasma AG concentrations and hunger scores after the end of walking in water and on land also indicated that AG concentrations were more likely to be high in those with higher hunger

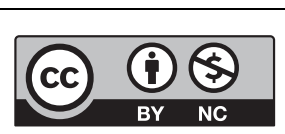

This work is licensed under a Creative Commons Attribution-NonCommercial 4.0 International License. 
scores. Broom and coworkers (36) also found that decreases in AG concentrations during running exercise positively correlated with decreases in hunger scores. One of the possible interpretations of this result is that in this study setting, AG was more closely involved in 'exercise-induced anorexia' (43). These findings provide novel information regarding the influence of walking in water on the acute regulation of appetite and AG. In addition, we speculated that $A G$ concentrations were significantly lower in the water trial than in the land trial due to an increase in leg fatigue, and IL-6 may be involved in resistance exercise because of water viscosity and resistance as well as differences in muscle activity during walking in water. Broom and coworkers (5) reported that treadmill running suppressed AG, whereas resistance exercise promoted it.

There were some potential limitations to the present study. Subjects in the present study were young, healthy males; therefore, we do not know whether our results may be generalized to other populations such as females, the elderly or overweight and obese individuals. We previously demonstrated that gut hormone (AG, GLP-1 and PYY) concentrations showed the same pattern during aerobic exercise in obese and non-obese subjects (10). Therefore, we speculated that similar results may be obtained from overweight and obese individuals in the present study. A sex difference had a significant influence on appetite sensations (37). In addition, gut hormones and appetite respond differently to exercise in males and females $(38,39)$. This sex difference is prominently attributed to the menstrual cycle (40). Therefore, we focused on males and excluded females. Further studies are needed in order to clarify whether there is a sex difference in gut hormones and appetite after walking in water. Furthermore, body temperature was not measured in the present study. Previous studies demonstrated that changes in body temperature during and after exercise may affect appetite, hormone circulation and food intake. Shorten and coworkers (41) demonstrated that EI was greater after exercise at a neutral temperature $\left(25^{\circ} \mathrm{C}\right)$ than under resting conditions, but was similar between rest and exercise in the heat $\left(36^{\circ} \mathrm{C}\right)$. Other studies examined the effects of exercise performed in a cold environment on appetite. White and coworkers (42) reported that EI was significantly higher after exercise in cold water $\left(20^{\circ} \mathrm{C}\right)$ than in neutral water $\left(33^{\circ} \mathrm{C}\right)$ and resting trials. In the present study, body temperature may have differed between the two experimental trials (walking in water and on land trials) even though the temperature was the

$$
\text { http://www.endocrineconnections.org }
$$

same as air temperature $\left(25^{\circ} \mathrm{C}\right)$ when walking in water and on land. Differences in body temperature when walking in water and on land may have contributed to differences in hunger and hormone concentrations between the two conditions. In the future, a clearer understanding of the relationship between body temperature and gut hormone concentrations during walking in water may assist in the development of new exercise programs to prevent and treat lifestyle diseases such as obesity, type 2 diabetes and hyperlipidemia. Another limitation is that the time of observations was short in the present study. Most studies indicated that individuals did not compensate for energy expended during exercise in the immediate hours after exercise by altering food intake (22). In addition, subjective feelings of hunger are suppressed during and after exercise; however, this suppression was short-lived (43). In the future, appetite sensations need to be measured for a short time after the meal in order to examine differences in the satiating effects of a meal following exercise in water vs. that on land. Additionally, we cannot rule out the possibility that cognitive or environmental factors affected our results even though we attempted to carefully exclude confounding variables based on the choice of study design. In previous studies on appetite, subjects were instructed to eat ad libitum (23). However, under these circumstances, food intake may be biased by cognitive factors such as the belief that 'food is a reward for exercise' (7). In the present study, a common test meal of noodles was prepared in order for subjects to be unaware of food intake during the test $(8,9,10)$.

In conclusion, we herein demonstrated that GLP-1 concentrations were significantly higher and $A G$ concentrations were significantly lower when walking in water than on land. These results suggest that changes in gut hormone concentrations during walking in water contribute to the exercise-induced suppression of appetite. Our results may contribute to exercise guidance for maintaining and improving body weight and mass for health.

\section{Declaration of interest}

The authors declare that there is no conflict of interest that may be perceived as prejudicing the impartiality of the research reported.

\section{Funding}

This study was supported in part by grants from the Kao Research Council for the Study of Healthcare Science and the Japanese Ministry of Education, Culture Sports, Science and Technology Grant-In-Aid for Scientific Research 17 K13200. 


\section{Author contribution statement}

Shin-ya Ueda; designed the experiments, developed analyses and drafted and revised the manuscript. Hidehiro Nakahara, Eriko Kawai, Tatsuya Usui and Shintaro Tsuji; collected, analyzed and provided initial interpretations of the data. Tadayoshi Miyamoto; collected and analyzed the data, and reviewed and revised the manuscript.

\section{References}

1 Bray GA. Afferent signals regulating food intake. Proceedings of the Nutrition Society 200059 373-384. (https://doi.org/10.1017/ S0029665100000422)

2 Huda MS, Wilding JP \& Pinkney JH. Gut peptides and the regulation of appetite. Obesity Reviews 20067 163-182. (https://doi.org/10.1111/ j.1467-789X.2006.00245.X)

3 Kojima M, Hosoda H, Date Y, Nakazato M, Matsuo H \& Kangawa K. Ghrelin is a growth-hormone-releasing acylated peptide from stomach. Nature 1999402 656-660. (https://doi.org/10.1038/45230)

4 Li JB, Asakawa A, Li Y, Cheng K \& Inui A. Effects of exercise on the levels of peptide YY and ghrelin. Experimental and Clinical Endocrinology and Diabetes 2011119 163-166. (https://doi. org/10.1055/s-0030-1262790)

5 Broom DR, Batterham RL, King JA \& Stensel DJ. Influence of resistance and aerobic exercise on hunger, circulating levels of acylated ghrelin, and peptide YY in healthy males. American Journal of Physiology: Regulatory, Integrative and Comparative Physiology 2009 296 R29-R35. (https://doi.org/10.1152/ajpregu.90706.2008)

6 Cheng MH, Bushnell D, Cannon DT \& Kern M. Appetite regulation via exercise prior or subsequent to high-fat meal consumption. Appetite 200952 193-198. (https://doi.org/10.1016/j. appet.2008.09.015)

7 Martins C, Morgan LM, Bloom SR \& Robertson MD. Effects of exercise on gut peptides, energy intake and appetite. Journal of Endocrinology 2007193 251-258. (https://doi.org/10.1677/JOE-060030)

8 Ueda SY, Miyamoto T, Nakahara H, Shishido T, Usui T, Katsura Y, Yoshikawa T \& Fujimoto $S$. Effects of exercise training on gut hormone levels after a single bout of exercise in middleaged Japanese women. Springerplus 20132 83. (https://doi. org/10.1186/2193-1801-2-83)

9 Ueda SY, Yoshikawa T, Katsura Y, Usui T \& Fujimoto S. Comparable effects of moderate intensity exercise on changes in anorectic gut hormone levels and energy intake to high intensity exercise. Journal of Endocrinology 2009203 357-364. (https://doi.org/10.1677/JOE-090190)

10 Ueda SY, Yoshikawa T, Katsura Y, Usui T, Nakao H \& Fujimoto S. Changes in gut hormone levels and negative energy balance during aerobic exercise in obese young males. Journal of Endocrinology 2009 201 151-159. (https://doi.org/10.1677/JOE-08-0500)

$11 \mathrm{Lim}$ KI \& Rhi SY. The effects of landed and aquatic treadmill walking at moderate intensity on heart rate, energy expenditure and catecholamine. Journal of Exercise Nutrition and Biochemistry 201418 197-203. (https://doi.org/10.5717/jenb.2014.18.2.197)

12 Balaguera-Cortes L, Wallman KE, Fairchild TJ \& Guelfi KJ. Energy intake and appetite-related hormones following acute aerobic and resistance exercise. Applied Physiology, Nutrition, and Metabolism 2011 36 958-966. (https://doi.org/10.1139/h11-121)

13 Goto K, Shioda K \& Uchida S. Effect of 2 days of intensive resistance training on appetite-related hormone and anabolic hormone responses. Clinical Physiology and Functional Imaging 201333 131-136. (https://doi.org/10.1111/cpf.12005)

14 Deighton K, Barry R, Connon CE \& Stensel DJ. Appetite, gut hormone and energy intake responses to low volume sprint interval and traditional endurance exercise. European Journal of Applied
Physiology 2013113 1147-1156. (https://doi.org/10.1007/s00421012-2535-1)

15 Kawano H, Mineta M, Asaka M, Miyashita M, Numao S, Gando Y, Ando T, Sakamoto S \& Higuchi M. Effects of different modes of exercise on appetite and appetite-regulating hormones. Appetite 2013 66 26-33. (https://doi.org/10.1016/j.appet.2013.01.017)

16 Lambert CP, Flynn MG, Braun WA \& Boardley DJ. The effects of swimming and running on energy intake during 2 hours of recovery. Journal of Sport Medicine and Physical Fitness 199939 348-354.

17 King JA, Wasse LK \& Stensel DJ. The acute effects of swimming on appetite, food intake, and plasma acylated ghrelin. Journal of Obesity 20112011 351628. (https://doi.org/10.1155/2011/358205)

18 Craig AB Jr \& Dvorak M. Thermal regulation of man exercising during water immersion. Journal of Applied Physiology 196825 28-35.

19 Flint A, Raben A, Blundell JE \& Astrup A. Reproducibility, power and validity of visual analogue scales in assessment of appetite sensations in single test meal studies. International Journal of Obesity and Related Metabolic Disorders 200024 38-48. (https://doi.org/10.1038/ sj.ijo.0801083)

20 Borg GA. Psychophysical bases of perceived exertion. Medicine and Science in Sports and Exercise 198214 377-381.

21 Miyamoto T, Bailey DM, Nakahara H, Ueda S, Inagaki M \& Ogoh S. Manipulation of central blood volume and implications for respiratory control function. American Journal of Physiology: Heart and Circulatory Physiology 2014306 H1669-H1678. (https://doi. org/10.1152/ajpheart.00987.2013)

22 Schubert MM, Desbrow B, Sabapathy S \& Leveritt M. Acute exercise and subsequent energy intake. A meta-analysis. Appetite 201363 92-104. (https://doi.org/10.1016/j.appet.2012.12.010)

23 Schubert MM, Sabapathy S, Leveritt M \& Desbrow B. Acute exercise and hormones related to appetite regulation: a meta-analysis. Sports Medicine 201444 387-403. (https://doi.org/10.1007/s40279-0130120-3)

24 Anini Y, Hansotia T \& Brubaker PL. Muscarinic receptors control postprandial release of glucagon-like peptide-1: in vivo and in vitro studies in rats. Endocrinology 2002143 2420-2426. (https://doi. org/10.1210/endo.143.6.8840)

25 Dumoulin V, Dakka T, Plaisancie P, Chayvialle JA \& Cuber JC. Regulation of glucagon-like peptide-1-(7-36) amide, peptide YY, and neurotensin secretion by neurotransmitters and gut hormones in the isolated vascularly perfused rat ileum. Endocrinology 1995136 5182-5188. (https://doi.org/10.1210/endo.136.11.7588257)

26 Hansen L, Lampert S, Mineo H \& Holst JJ. Neural regulation of glucagon-like peptide-1 secretion in pigs. American Journal of Physiology: Endocrinology and Metabolism 2004287 E939-E947. (https://doi.org/10.1152/ajpendo.00197.2004)

27 Herrmann-Rinke C, Vöge A, Hess M \& Göke B. Regulation of glucagon-like peptide- 1 secretion from rat ileum by neurotransmitters and peptides. Journal of Endocrinology 1995147 25-31. (https://doi.org/10.1677/joe.0.1470025)

28 Plaisancie P, Bernard C, Chayvialle JA \& Cuber JC. Regulation of glucagon-like peptide-1-(7-36) amide secretion by intestinal neurotransmitters and hormones in the isolated vascularly perfused rat colon. Endocrinology 1994135 2398-2403. (https://doi. org/10.1210/endo.135.6.7988423)

29 Holst JJ. The physiology of glucagon-like peptide 1. Physiological Reviews 200787 1409-1439. (https://doi.org/10.1152/ physrev.00034.2006)

30 Rocca AS \& Brubaker PL. Role of the vagus nerve in mediating proximal nutrient-induced glucagon-like peptide-1 secretion. Endocrinology 1999140 1687-1694. (https://doi.org/10.1210/ endo.140.4.6643)

31 Miyamoto T, Oshima Y, Ikuta K \& Kinoshita H. The heart rate increase at the onset of high-work intensity exercise is accelerated by central blood volume loading. European Journal of Applied Physiology 200696 86-96. (https://doi.org/10.1007/s00421-005-0052-1) http://www.endocrineconnections.org https://doi.org/10.1530/EC-17-0323
(๔) 2018 The authors Published by Bioscientifica Ltd
This work is licensed under a Creative Commons Attribution-NonCommercial 4.0 International License. 
32 Ellingsgaard H, Hauselmann I, Schuler B, Habib AM, Baggio LL, Meier DT, Eppler E, Bouzakri K, Wueest S, Muller YD, et al. Interleukin-6 enhances insulin secretion by increasing glucagon-like peptide-1 secretion from L cells and alpha cells. Nature Medicine 2011 17 1481-1489. (https://doi.org/10.1038/nm.2513)

33 Maeda A, Miyagawa J, Miuchi M, Nagai E, Konishi K, Matsuo T, Tokuda M, Kusunoki Y, Ochi H, Murai K, et al. Effects of the naturally-occurring disaccharides, palatinose and sucrose, on incretin secretion in healthy non-obese subjects. Journal of Diabetes Investigation 20134 281-286. (https://doi.org/10.1111/jdi.12045)

34 King JA, Wasse LK, Stensel DJ \& Nimmo MA. Exercise and ghrelin. A narrative overview of research. Appetite 201368 83-91. (https://doi. org/10.1016/j.appet.2013.04.018)

35 Stengel A, Goebel M, Wang L \& Taché Y. Ghrelin, des-acyl ghrelin and nesfatin-1 in gastric X/A-like cells: role as regulators of food intake and body weight. Peptides 201031 357-369. (https://doi. org/10.1016/j.peptides.2009.11.019)

36 Broom DR, Stensel DJ, Bishop NC, Burns SF \& Miyashita M. Exercise-induced suppression of acylated ghrelin in humans. Journal of Physiology 2007102 2165-2171. (https://doi.org/10.1152/ japplphysiol.00759.2006)

37 Painchaud Guérard G, Lemieux S, Doucet É, Pomerleau S \& Provencher V. Influence of nutrition claims on appetite sensations according to sex, weight status, and restrained eating. Journal of Obesity 20162016 9475476. (https://doi.org/10.1155/2016/9475476)
38 Hazell TJ, Townsend LK, Hallworth JR, Doan J \& Copeland JL. Sex differences in the response of total PYY and GLP-1 to moderateintensity continuous and sprint interval cycling exercise. European Journal of Applied Physiology 2017117 431-440. (https://doi. org/10.1007/s00421-017-3547-7)

39 Kawano H, Motegi F, Ando T, Gando Y, Mineta M, Numao S, Miyashita M, Sakamoto S \& Higuchi M. Appetite after rope skipping may differ between males and females. Obesity Research and Clinical Practice 20126 e91-e174. (https://doi.org/10.1016/j. orcp.2011.06.001)

40 Scheid JL \& De Souza MJ. Menstrual irregularities and energy deficiency in physically active women: the role of ghrelin, PYY and adipocytokines. Medicine and Sport Science 201055 82-102. (https:// doi.org/10.1159/000321974)

41 Shorten AL, Wallman KE \& Guelfi KJ. Acute effect of environmental temperature during exercise on subsequent energy intake in active men. American Journal of Clinical Nutrition 200990 1215-1221. (https://doi.org/10.3945/ajcn.2009.28162)

42 White LJ, Dressendorfer RH, Holland E, McCoy SC \& Ferguson MA. Increased caloric intake soon after exercise in cold water. International Journal of Sport Nutrition and Exercise Metabolism 200515 38-47. (https://doi.org/10.1123/ijsnem.15.1.38)

43 King NA, Burley VJ \& Blundell JE. Exercise-induced suppression of appetite: effects on food intake and implications for energy balance. European Journal of Clinical Nutrition 199448 715-724.

Received in final form 31 October 2017

Accepted 20 November 2017

Accepted Preprint published online 20 November 2017 http://www.endocrineconnections.org https://doi.org/10.1530/EC-17-0323
(C) 2018 The authors Published by Bioscientifica Ltd

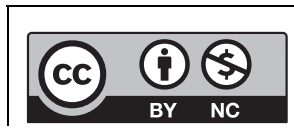

This work is licensed under a Creative Commons Attribution-NonCommercial 4.0 International License. 